\title{
Electrochemical Study of $\beta$-Cyclodextrin Binding with Ferrocene Tethered onto a Gold Surface via PAMAM Dendrimers
}

\author{
E. Bustos, ${ }^{a}$ J. Manríquez, ${ }^{a}$ E. Juaristi, ${ }^{b}$ Thomas W. Chapman ${ }^{a}$ and Luis A. Godínez ${ }^{*, a}$ \\ ${ }^{a}$ Electrochemistry Department, Centro de Investigación y Desarrollo Tecnológico en Electroquímica, \\ Parque Tecnológico Querétaro, Sanfandila, Pedro Escobedo, 76703, PO Box 064, Querétaro, Mexico \\ ${ }^{b}$ Chemistry Department, Centro de Investigación y de Estudios Avanzados del I.P.N., \\ PO Box 14-740, 07000 Mexico, DF, Mexico
}

\begin{abstract}
Este artigo descreve a fixação de ferrocenos $(\mathrm{Fc})$ sobre eletrodos policristalinos de ouro, por filmes dendrímeros de poliamidoamina (PAMAM). A superfície eletroativa fornece uma rota viável para investigar quantitativamente a ligação do ferroceno com a ciclodextrina (CD). Em particular, as medidas eletroquímicas, revelam o efeito das interações adsorção-adsorção sobre a constante de associação $\mathrm{K}$, na interface eletrodo-eletrólito, durante a formação do complexo de 1:1 $\beta \mathrm{CD} \cdot \mathrm{Fc}$. Os resultados obtidos a partir da investigação da isoterma de adsorção de Frumkin indicam que as interações podem ter um forte impacto na afinidade do $\beta C D$ com as superfícies do ferrocenil modificado, estudadas aqui. A técnica apresentada pode ser útil para investigar outras reações de ligação entre hóspede-hospedeiro.
\end{abstract}

This paper describes the tethering of ferrocene $(\mathrm{Fc})$ onto polycrystalline gold electrodes by immobilized polyamidoamine (PAMAM) dendrimers films. The resulting electroactive surface provides a viable route for investigating quantitatively the host-guest binding of ferrocene with cyclodextrin (CD). In particular, electrochemical measurements reveal the effect of adsorbateadsorbate interactions on the association constant $K$ for the formation of the $1: 1 \beta \mathrm{CD} \bullet \mathrm{Fc}$ complex at the electrode-electrolyte interface. The results obtained from fitting the Frumkin isotherm to the adsorption data indicate that adsorbate-adsorbate interactions can have a strong impact on the $\beta C D$ affinity for the ferrocenyl-modified surfaces studied here. The technique presented may be useful for investigating other host-guest binding reactions.

Keywords: dendrimers, $\beta$-cyclodextrin, ferrocene, inclusion complexes

\section{Introduction}

Supramolecular chemistry studies non-covalent interactions, such as electrostatic forces, hydrogen binding, solvophobic effects and cation- $\pi$ interactions, to understand the structure-activity relationships among a wide variety of molecules. In this context, supramolecular-chemistry researchers often investigate with electrochemical studies the formation of inclusion complexes by following the changes in the redox-activity behavior of an electroactive guest that is bonded non-covalently with a non-electroactive host. ${ }^{1-3}$ Many inclusion complexes involve a basket-like host, which acts as a receptor of a guest inside its cavity and sequesters the guest, inhibiting the electroactivity of the latter.

*e-mail: lgodinez@cideteq.mx
Ferrocene or bis(cyclopentadienyl)iron(II) $(\mathrm{Fc})$ is probably the most common electroactive guest studied in supramolecular electrochemistry due to its synthetic accessibility and its convenient electrochemical properties. ${ }^{1}$ The most common hosts in Fc studies are the Schandinger's dextrins or cyclodextrins (CD). Since these latter molecules have a basket-like structure, their cavities offer a partially hydrophobic environment that promotes the formation of inclusion complexes with those molecules having the proper size and affinity. For instance, it has been reported extensively that ferrocene can be readily inserted inside the cavity of the water-soluble $\beta$-cyclodextrin $(\beta C D))^{2,3}$ The predominant driving force that promotes the formation of the 1:1 host-guest complex $\beta \mathrm{CD} \bullet \mathrm{Fc}$ is the so-called hydrophobic effect. ${ }^{4}$

Polyamidoamine (PAMAM) dendrimers are branched polymers whose well-defined terminal groups provide 
specific solubility and reactivity properties. ${ }^{5,6}$ The covalent incorporation of redox-active groups into dendrimers is an important area of chemical research, particularly employing these macromolecules as scaffolds for controlling the number and position of multiple functional groups on their periphery. Thus, such materials can be used as construction blocks to produce modified electrode surfaces having molecularrecognition properties for sensing enzymes, ${ }^{7,8}$ genetic materials, ${ }^{9,10}$ antibodies, ${ }^{11,12}$ and other molecules showing biological importance. ${ }^{13}$

Studies into the nature of the bonds involved in the supramolecular interactions between a non-electroactive host (e.g. $\beta C D$ ) and an electroactive guest (e.g. Fc), have been conducted typically in aqueous media by monitoring the activity of the free guest molecule with an electrochemical probe. For example, the bonding of Fc to $\beta C D$ can be followed by assuming that electrontransfer does not take place from the inclusion complex. Voltammetric measurements are then interpreted in terms of a CE mechanism in which the complex must dissociate prior to electrochemical oxidation: ${ }^{14}$

$\beta \mathrm{CD} \bullet \mathrm{Fc} \rightleftharpoons \beta \mathrm{CD}+\mathrm{Fc}$

$\mathrm{Fc} \rightleftharpoons \mathrm{Fc}^{+}+\mathrm{e}^{-}$

On this basis, Kaifer and co-workers have demonstrated that the association constant $K$ for the $1: 1$ inclusion complex $\beta \mathrm{CD} \bullet \mathrm{Fc}$ established in solution between dendrons bearing a single ferrocene group and $\beta C D$ hosts is strongly dependent of the size of the dendron. ${ }^{14}$ Specifically, the largest monoferrocene-bearing dendron studied showed the smallest value for $K\left(50 \mathrm{~L} \mathrm{~mol}^{-1}\right)$, whereas the smallest dendron exhibited the highest value for this parameter $\left(950 \mathrm{~L} \mathrm{~mol}^{-1}\right)$. According to the authors, this phenomenon was explained satisfactorily by assuming that additional peripheral groups surrounding the ferrocenyl unit attached to these dendrons produce a steric hindrance that shifts the equilibrium of Reaction 1 to the right.

In this paper we present covalent modification of polycrystalline gold electrodes with attached ferrocene via linkages through PAMAM dendrimers of various sizes. With such electrodes modified with immobilized Fc we have conducted electrochemical studies that allow to investigate the magnitude of the binding forces related to the interfacial formation of 1:1 inclusion complexes $\beta C D \bullet F c$ by attachment of $\beta C D$ from solution. This approach offers an alternative procedure to homogeneoussolution studies that can also reveal interesting properties of such electrodes.

\section{Experimental}

\section{Reagents and Instrumentation}

Commercially available PAMAM ${ }^{\mathrm{TM}}$ dendrimers of generations 1.0 (PG1), 2.0 (PG2), 3.0 (PG3) and 4.0 (PG4) (bearing 8, 16, 32 and 64 terminal $-\mathrm{NH}_{2}$ groups, respectively) and $\beta$-cyclodextrin hydrate $(\beta C D)$ of the best commercial quality were used. Similarly, reagent-grade 11-mercaptoundecanoic acid (MUA; $\mathrm{HS}\left(\mathrm{CH}_{2}\right)_{10} \mathrm{COOH}$, 95\%), 1-(3-dimethylamino)propyl-3-ethylcarbodiimide hydrochloride (EDC; 98\%), and ferrocene monocarboxylic acid (FcCOOH; 97\%) were obtained from Aldrich. $\mathrm{Ru}\left(\mathrm{NH}_{3}\right)_{6} \mathrm{Cl}_{3}(99 \%)$ was provided by Strem Chemicals. Analytical-grade $\mathrm{NaF}, \mathrm{KH}_{2} \mathrm{PO}_{4}$ and $\mathrm{Na}_{2} \mathrm{HPO}_{4}$ were obtained from J.T. Baker and used for preparing aqueous electrolytic solutions with deionized water $\left(\rho \geq 18 \times 10^{-6} \Omega \mathrm{cm}\right)$. All chemical reagents were used without further purification.

Electrochemical experiments were performed at $298 \mathrm{~K}$ with a BAS Epsilon ${ }^{\mathrm{TM}}$ potentiostat. Cyclic voltammetry (CV) was carried out in a $10 \mathrm{~mL}$ BAS cell equipped with a platinum wire and a saturated calomel electrode (SCE) as counter and reference electrodes, respectively. Spherical polycrystalline-gold working electrodes were prepared by melting the tip of a gold wire $\left(99.999 \%\right.$, Premion $^{\mathrm{TM}}$ Alfa; $1.0 \mathrm{~mm}$ diameter) as was previously reported, ${ }^{16}$ resulting in beads having a roughness factor of about 1.1. ${ }^{17}$ All experiments were performed under an inert atmosphere by bubbling ultra-pure nitrogen (Praxair, grade 4.8) for at least 10 min. Computer fitting of $\mathrm{CV}$ data was carried out by means of the software MINSQ ${ }^{\mathrm{TM}}$ (Least Squares Parameter Estimation version 3.12 from MicroMath Inc.) installed in a $\mathrm{PC}$ based on a Pentium ${ }^{\mathrm{TM}}$ processor.

The true electroactive area of the gold electrodes $A$ $\left(0.02 \pm 0.005 \mathrm{~cm}^{2}\right)$ was estimated by fitting the RandlesŠevčik equation to plots of experimental cathodic peak current vs. potential scan rate, constructed with data from the reversible voltammetric responses for the fresh gold electrodes immersed in a neutral aqueous phosphate buffer (ionic strength, $\mathrm{I}=0.1$ ) containing the redox couple $\mathrm{Ru}\left(\mathrm{NH}_{3}\right)_{6}{ }^{3+} \mid \mathrm{Ru}\left(\mathrm{NH}_{3}\right)_{6}{ }^{2+}\left(0.5 \times 10^{-3} \mathrm{~mol} \mathrm{~L}^{-1} \mathrm{Ru}\left(\mathrm{NH}_{3}\right)_{6} \mathrm{Cl}_{3}\right) .{ }^{18}$ Voltammograms of the Fc-modified electrodes were taken in $0.1 \mathrm{~mol} \mathrm{~L}^{-1} \mathrm{KF}$ at $298 \mathrm{~K}$.

\section{Surface functionalization}

Figure 1 outlines the procedures used to functionalize and modify the gold electrodes. In Step 1 (Figure 1) clean gold surfaces were functionalized by means of thiol-linked self-assembled monolayers (SAM) of 11-mercaptoundecanoic acid (MUA) by immersing them 


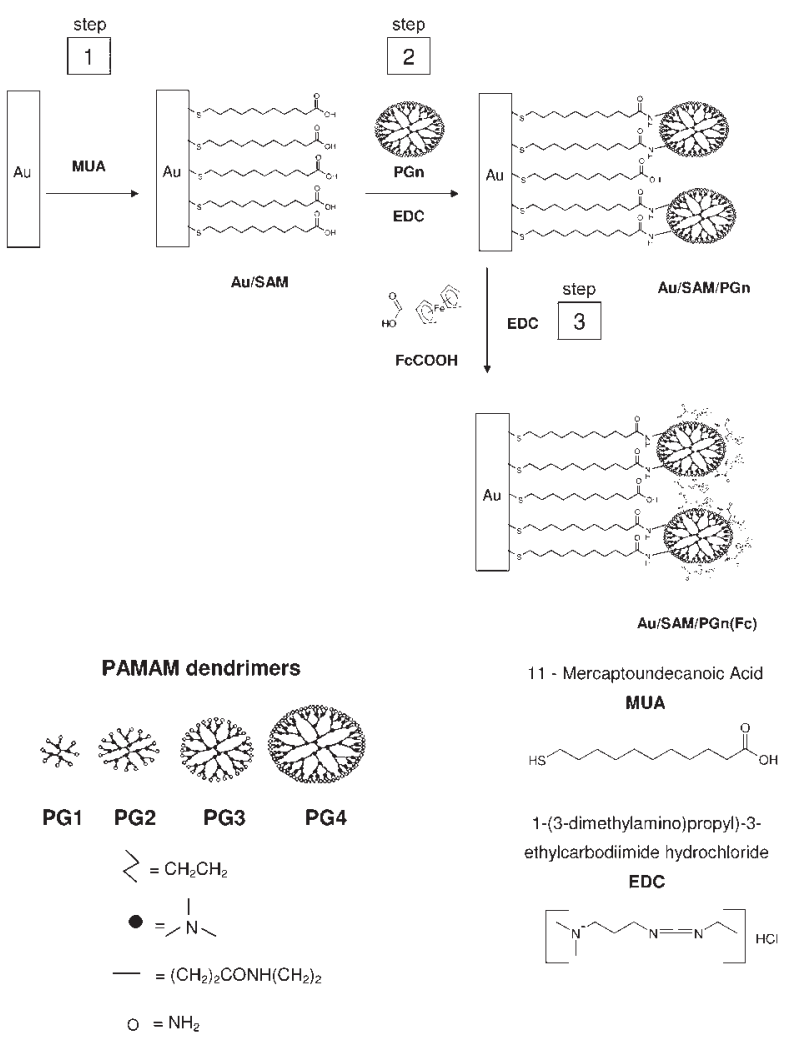

Figure 1. Schematic outline of the process used to prepare the gold electrodes compared in this study: (Step 1) Thiol modification of the gold surfaces to form Au/SAM; (Step 2) Dendrimer functionalization of the thiolated gold surfaces to produce $\mathrm{Au} / \mathrm{SAM} / \mathrm{PGn}$, where $\mathrm{n}=1,2,3$, 4; and (Step 3) Tethering of ferrocenyl moieties onto the immobilized dendrimers generating Au/SAM/PGn-Fc.

in $1 \times 10^{-3} \mathrm{~mol} \mathrm{~L}^{-1}$ MUA methanolic solutions at $298 \mathrm{~K}$ for $24 \mathrm{~h} .{ }^{19}$ The presence of the thiols on the metallic substrates was confirmed by their electrochemical desorption in aqueous $0.5 \mathrm{~mol} \mathrm{~L}^{-1} \mathrm{KOH}$, as revealed by cathodic $\mathrm{CV}$ peaks close to $-1.0 \mathrm{~V} v s$. SCE (data not shown). This reduction peak arises from the reaction: ${ }^{18,20}$

$$
\mathrm{Au} / \mathrm{S}\left(\mathrm{CH}_{2}\right)_{10} \mathrm{COOH}+\mathrm{e}^{-} \rightarrow \mathrm{Au}+{ }^{-} \mathrm{S}\left(\mathrm{CH}_{2}\right)_{10} \mathrm{COOH}
$$

MUA surface coverage $\Gamma_{\text {MUA }}$ was calculated to be $9.05 \times 10^{-11} \mathrm{~mol} \mathrm{~cm}^{-2}$ by means of Faraday's law

$\Gamma_{\mathrm{MUA}}=\mathrm{Q}_{\mathrm{MUA}}(\mathrm{FA})^{-1}$

where the faradic charge $\left(\mathrm{Q}_{\mathrm{MUA}}\right)$ associated with the desorptive process (equation 4) was estimated by integration of the relevant cathodic peak. If it is assumed that a closely packed monolayer of MUA should have a coverage $\left(\Gamma_{\text {MUA, }}\right)$ of $1.2 \times 10^{-10} \mathrm{~mol} \mathrm{~cm}{ }^{-2},{ }^{21}$ the current procedure was sucessful in forming nearly a complete monolayer of MUA on the gold surface according to the ratio $\Gamma_{\mathrm{MUA}} / \Gamma_{\mathrm{MUA}, \mathrm{m}}$ equal to $0.75 .^{22}$
During Step 2 (Figure 1), PAMAM dendrimers were linked chemically to the functionalized gold electrodes by promoting the creation of amide bonds $\mathrm{NH}(\mathrm{CO})$ between the $\mathrm{COOH}$ ends of the MUA and amine groups $\left(\mathrm{NH}_{2}\right)$ on the dendrimers. This was achieved by immersing the thiolated gold substrates in methanolic solutions containing $5 \times 10^{-3} \mathrm{~mol} \mathrm{~L}^{-1} \mathrm{EDC}$ (to promote the creation of the amide bonds) and $21 \times 10^{-6} \mathrm{~mol} \mathrm{~L}^{-1}$ PAMAM dendrimer of Generation 1.0 (PG1), 2.0 (PG2), 3.0(PG3) or 4.0 (PG4) for $12 \mathrm{~h}$ at $298 \mathrm{~K} .{ }^{23}$ Subsequently, the dendrimer-functionalized gold surfaces were washed by dipping them in gently stirred $\mathrm{MeOH}$ at room temperature. In Step 3 (Figure 1) the dendrimer-bearing substrates were then immersed in neutral aqueous phosphate buffer containing $1 \times 10^{-3} \mathrm{~mol} \mathrm{~L}^{-1}$ FcCOOH with $5 \times 10^{-3} \mathrm{~mol} \mathrm{~L}^{-1} \mathrm{EDC}$ for $24 \mathrm{~h}$ at $298 \mathrm{~K}$ in order to tether the ferrocenyl moieties to the dendritic adsorbates through another set of amide bonds. ${ }^{24,16}$ The resulting electrode surfaces were washed by dipping them in gently stirred clean buffer solutions.

\section{Results and Discussion}

\section{Tethering of ferrocene onto the gold electrodes}

The attachment of the Fc moieties onto the gold substrates was revealed by the voltammograms shown in Figure 2, in which characteristic peaks appear around $0.5 \mathrm{~V}$ vs. SCE for the four electrodes: (A) Au/SAM/PG1-Fc, (B) Au/SAM/PG2-Fc, (C) Au/SAM/PG3-Fc, and (D) $\mathrm{Au} / \mathrm{SAM} / \mathrm{PG} 4-\mathrm{Fc}$ in $0.1 \mathrm{~mol} \mathrm{~L}^{-1} \mathrm{KF}$ at $298 \mathrm{~K}$. Table 1 gives the estimates of the redox potentials obtained from the peaks in Figure 2, which correspond to the redox reaction:

$$
\mathrm{Au} / \mathrm{SAM} / \mathrm{PGn}-\mathrm{Fc} \rightarrow \mathrm{Au} / \mathrm{SAM} / \mathrm{PGn}-\mathrm{Fc}^{+}+\mathrm{e}^{-}
$$

Inspection of Figures 2A-2D and Table 1 suggests that the electron transfer (ET) rate between the Fc moieties and the electrode substrate is strongly dependent on the

Table 1. Electrochemical parameters obtained from the CV responses in $0.1 \mathrm{~mol} \mathrm{~L}^{-1} \mathrm{KF}$ at $298 \mathrm{~K}$ for the four ferrocene-dendrimer-modified electrodes studied

\begin{tabular}{lcc}
\hline System & ${ }^{a} E_{f}^{0 \prime} / \mathrm{V} v s . \mathrm{SCE}$ & $\Gamma_{F c} / 10^{-10} \mathrm{~mol} \mathrm{~cm}^{-2}$ \\
\hline Au/SAM/PG1-Fc & $b$ & 0.5 \\
Au/SAM/PG2-Fc & 0.50 & 2.0 \\
Au/SAM/PG3-Fc & 0.50 & 6.0 \\
Au/SAM/PG4-Fc & 0.51 & 6.5 \\
\hline
\end{tabular}

$a_{\text {estimated by the relationship } E_{f}^{0 \prime}=1 / 2\left(E_{p a, f}-E_{c p, f}\right) \text { for the free form }}$ of the ferrocenyl groups; ${ }^{b}$ not available because this system was only quasi-reversible. 

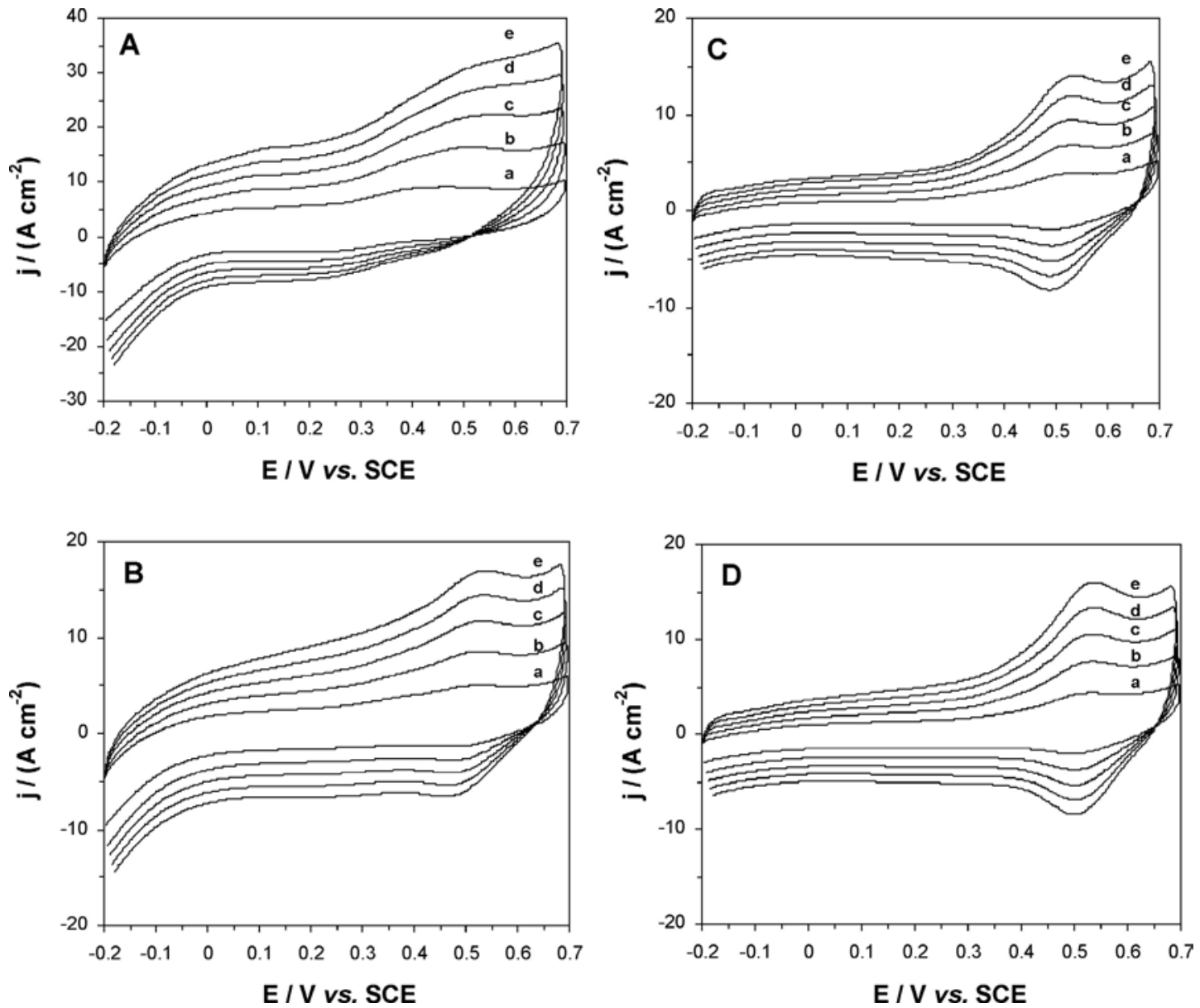

Figure 2. $\mathrm{CV}$ responses in aqueous $0.1 \mathrm{~mol} \mathrm{~L}^{-1} \mathrm{KF}$ at $298 \mathrm{~K}$ of the four types of electrode: (A) Au/SAM/PG1-Fc, (B) Au/SAM/PG2-Fc, (C) Au/SAM/ PG3-Fc, and (D) Au/SAM/PG4-Fc at (a) 0.1, (b) 0.2, (c) 0.3, (d) 0.4, and (e) $0.5 \mathrm{~V} \mathrm{~s}^{-1}$.

dendrimer generation $n$. For instance, the $\mathrm{CV}$ responses observed at different potential scan rates $(\mathrm{dE} / \mathrm{dt})$ appears to be quasi-reversible and highly capacitive for the Au/SAM/ PG1-Fc electrode (Figure 2A), whereas the responses for the three other surfaces, Au/SAM/PG2-Fc, Au/SAM/PG3$\mathrm{Fc}$ and $\mathrm{Au} / \mathrm{SAM} / \mathrm{PG} 4-\mathrm{Fc}$ (Figures 2B-2D, respectively), could be considered to be reversible and less capacitive. Indeed, it is not possible to identify clearly the peak potentials for the Generation-1 electrode because the peaks are obscured by the capacitative behavior. The reversible behavior observed with the three larger dendrimers and the trends seen in Table 1 may indicate that the attachment of larger dendrimers to the gold surface affects the structure of the interface to reduce the double-layer capacitance. Also, it is noted that the charge transfer (ET) between the Fc and the gold substrate, which occurs by electron-tunneling as reported by Kwak and co-workers, ${ }^{9,12}$ is actually facilitated by the larger dendrimers, at least up to Generation 4 .

The molar surface coverage of the tethered ferrocenyl groups to the modified gold electrodes $\Gamma_{\mathrm{Fc}}$ was estimated by integrating the charge under the anodic peaks in their
$\mathrm{CV}$ responses at $0.1 \mathrm{~V} \mathrm{~s}^{-1}$ (see Figure 2) and applying Faraday's law for a one-electron transfer. The results are given in Table 1. The estimated loadings were 2.0, 6.0 and $6.5 \times 10^{-10} \mathrm{~mol} \mathrm{~cm}^{-2}$ for Generations 2,3 and 4, respectively. Considering $4.5 \times 10^{-10} \mathrm{~mol} \mathrm{~cm}^{-2}$ as the typical value for a closely packed monolayer of directly adsorbed Fc units on a smooth surface, ${ }^{25,15}$ the experimental coverages for the Fc moieties in the tested systems were of similar magnitude and actually exceeded the planar monolayer value by $33 \%$ and $44 \%$ for the two largest dendrimers. This result shows that the kinetically fastest CV responses (see Figure 2) are obtained with the greatest loading of ferrocene and that the dendrimer tethering actually enhances the voltammetric response of adsorbed Fc.

\section{Binding of $\beta C D$ with $F c$ tethered to the dendrimer films}

The strength of the interactions that promote the formation of 1:1 Fc $\beta C D$ complexes between the $\beta C D$ hosts and the immobilized ferrocenyl guests on the dendrimer-modified electrodes films was investigated by 


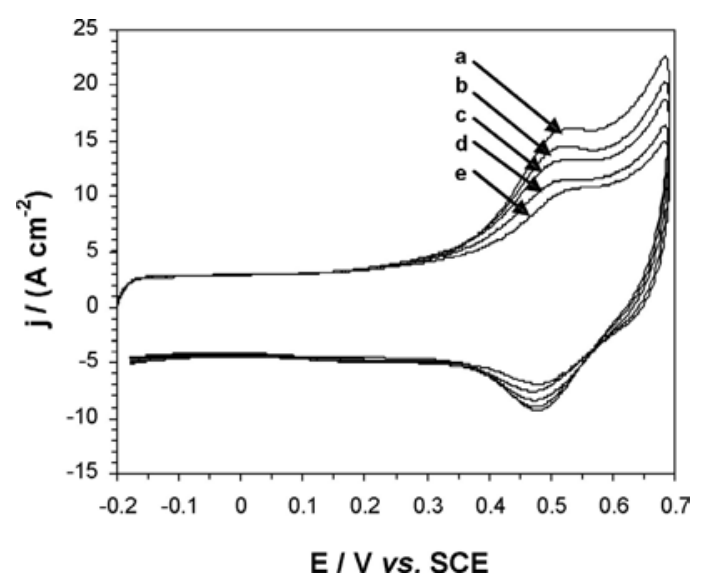

Figure 3. $\mathrm{CV}$ responses at $\mathrm{dE} / \mathrm{dt}=0.5 \mathrm{~V} \mathrm{~s}^{-1}$ in $0.1 \mathrm{~mol} \mathrm{~L}^{-1} \mathrm{KF}$ at $298 \mathrm{~K}$ at various concentrations of $\beta \mathrm{CD}$ for the modified electrodes $\mathrm{Au} / \mathrm{SAM} /$ PG4-Fc after the introduction of (a) 0 , (b) 0.001 , (c) 0.1 , (d) 0.5 , and (e) $1 \times 10^{-3} \mathrm{~mol} \mathrm{~L}^{-1} \beta \mathrm{CD}$. A similar trend was observed for the curves obtained for the systems Au/SAM/PG2-Fc and Au/SAM/PG3-Fc.

observing the adsorption of $\beta C D$ from aqueous solution as a function of $\beta C D$ concentration. Known amounts of $\beta C D$ were added to the $0.1 \mathrm{~mol} \mathrm{~L}^{-1} \mathrm{KF}$ solution, and the resulting change in the $\mathrm{Fc} \mathrm{CV}$ response was observed, as shown in Figure 3. These data were interpreted in terms of the following two reactions:

$\mathrm{Au} / \mathrm{SAM} / \mathrm{PGn}-\mathrm{Fc} \bullet \beta C D \rightleftharpoons \beta \mathrm{CD}+\mathrm{Au} / \mathrm{SAM} / \mathrm{PGn}-\mathrm{Fc}(6)$

$\mathrm{Au} / \mathrm{SAM} / \mathrm{PGn}-\mathrm{Fc} \rightleftharpoons \mathrm{Au} / \mathrm{SAM} / \mathrm{PGn}-\mathrm{Fc}^{+}+\mathrm{e}^{-}$

It was assumed that the ferrocene bound to cyclodextrin is not electroactive. Thus, the fractional coverage of Fc by $\beta C D, \theta$, may be estimated from the relation

$\theta=1-\frac{Q}{Q^{0}}$

where $Q$ and $Q^{o}$ represent the charges associated with the $\mathrm{CV}$ oxidation of $\mathrm{Fc}$ with and without $\beta \mathrm{CD}$, respectively, calculated from the curves shown in Figure 3. The experimental results for $\theta$ as a function of $\beta C D$ concentration are shown in Figure 4 as adsorption isotherms for the electrodes produced with dendrimers of Generations 2, 3, and 4 .

In order to understand better the binding process, the adsorption data in Figure 4 were fitted with the so-called Frumkin isotherm. ${ }^{18,26}$ Due to the combination of its simplicity and the relevant thermodynamic information that it provides, this model is by far the most popular isotherm which, also, has been successfully used for dendrimer modified electrode studies: $:^{27,28}$

$K C=\frac{\theta}{1-\theta} \exp (a \theta)$

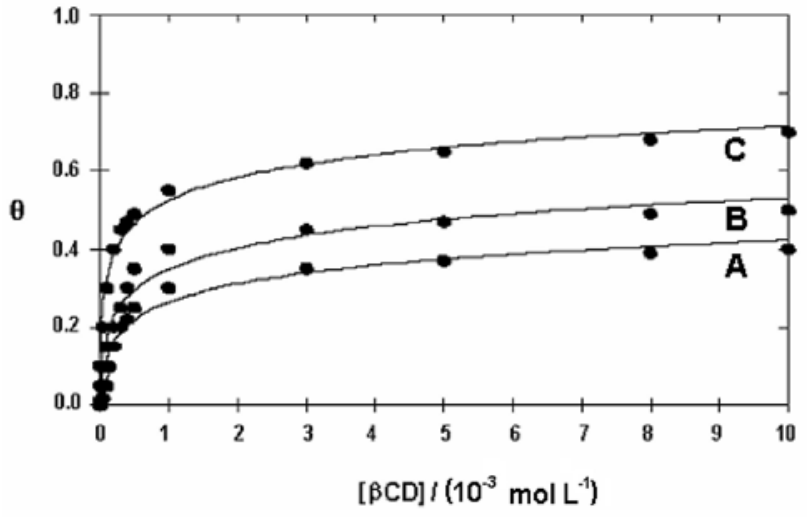

Figure 4. Adsorption isotherms of $\beta C D$ from $0.1 \mathrm{~mol} \mathrm{~L}^{-1} \mathrm{KF}$ at $298 \mathrm{~K}$ onto dendrimer-tethered ferrocene on the modified gold electrodes: (A) $\mathrm{Au} / \mathrm{SAM} / \mathrm{PG} 2-\mathrm{Fc}$, (B) Au/SAM/PG3-Fc, and (C) Au/SAM/PG4-Fc. Experimental points derived from Figure $3(\bullet)$ were fitted to the Frumkin isotherm model, Equation 9 (-).

where $C$ is the molar concentration of $\beta C D$ in solution, and $K$ stands for the apparent association constant related to the formation of the $\mathrm{Fc} \bullet \beta \mathrm{CD}$ complexes (equal to the reciprocal of the equilibrium constant for equation 6), which may be related to the free energy of the $\beta C D$ adsorption in the limit of very low surface coverage by $\beta \mathrm{CD}, \Delta G_{a d s}^{\mathrm{t}=0}$, according to the relation

$K=\left(1 / 55.5 \mathrm{molL}^{-1}\right) \exp \left(-\Delta G_{a d s}^{\theta=0} / R T\right)$

Equation 9 is derived taking into account lateral interactions between the adsorbed molecules. Thus, the parameter $a$ reflects the strength of the intermolecular interactions between $\beta C D$ adsorbates, which may be considered dependant on the dendritic size, because of the changing surface geometry. Assuming that the ferrocenyl guests immobilized on the smallest size dendrimers might be confined more closely than those borne on the larger dendrimers, it could be expected that the largest adsorbateadsorbate repulsive interactions should be observed for the former situation and decrease gradually as an inverse function of the dendritic generation. ${ }^{29-33}$

Table 2 gives the values of $K, \Delta G_{a d s}^{\mathrm{t}=0}$, and $a$ that were obtained by fitting the Frumkin-isotherm curves to the data in Figure 4. As it can be seen from the fitted values, the association constant $K$ for adsorption onto the immobilized Fc varied inversely with the dendritic size, and $\Delta G_{a d s}^{\mathrm{t}=0}$ became more negative. Thus, the $\beta C D$ adsorption becomes thermodynamically more spontaneous when dendrimer size increases. Consistent with these observations, the interaction parameter $a$ decreased with dendrimer size as well.

Although Table 2 reveals that the magnitudes of the parameters $K$ and $\Delta G_{a d s}^{\mathrm{t}=0}$ for CD binding to the tethered 
Table 2. Binding parameters for the association of the $\beta C D$ host with the immobilized dendrimer-tethered $\mathrm{Fc}$ at $298 \mathrm{~K}$ in aqueous $0.1 \mathrm{~mol} \mathrm{~L}^{-1} \mathrm{KF}$

\begin{tabular}{lccc}
\hline System & $K /\left(\mathrm{L} \mathrm{mol}^{-1}\right)$ & $a$ & $\Delta G_{a d s}^{\mathrm{t}=0} /\left(\mathrm{kJ} \mathrm{mol}^{-1}\right)$ \\
\hline $\begin{array}{l}\text { Au/SAM/PG2- } \\
\text { Fc } \bullet C D\end{array}$ & $5.0 \pm 0.5$ & $10.02 \pm 1.06$ & -13.94 \\
Au/SAM/PG3- & $10.4 \pm 1.4$ & $8.55 \pm 1.10$ & -15.76 \\
Fc $\beta C D$ & & & \\
Au/SAM/PG4- & $66.6 \pm 8.1$ & $7.83 \pm 0.85$ & -20.36 \\
Fc $\beta C D$ & &
\end{tabular}

ferrocene are small and comparable to some values previously reported for similar species in aqueous media, ${ }^{34}$ the Fc $\bullet \beta C D$ binding was expected to be larger (on the order of $10^{3} \mathrm{~L} \mathrm{~mol}^{-1}$ ) on the basis of other measurements of this interaction in aqueous medium. ${ }^{14}$ A possible explanation for our observations considers that the inclusion of ferrocene units inside the cyclodextrin cavity is mainly controlled by a positive entropic change $\left(\Delta S^{\circ}\right)$ for the water molecules which, ${ }^{1,35}$ upon inclusion, are transferred from the hydrophobic basket-like cavity $\left(S_{H 2 O}^{O}\right.$, cavity $)$ of $\beta \mathrm{CD}$ to the solution bulk $\left(S_{H 2 O \text {, bulk }}^{O}\right)$.

$\Delta S^{o}=S_{H 2 O, \text { bulk }}^{O}-S_{H 2 O, \text { cavity }}^{O}$

A similar entropy balance can be considered for the inclusion reaction carried out on the electrode-solution interface where $S_{H 2 O}^{O}$, interface represents the entropy of water molecules located in this region.

$\Delta S^{o}=S_{H 2 O, \text { interface }}^{0}-S_{H 2 O, \text { cavity }}^{O}$

Comparison of equations 11 and 12 allows to predict that the stability constants $K$ for the interfacial Fc $\beta C D$ complexes (see Table 2) must be lower ${ }^{36}$ than those observed in solution, ${ }^{14}$ if $S_{H 2 O}^{O}$, interface $<S_{H 2 O}^{O}$, bulk . This condition holds when we note that the dielectric constants, $\varepsilon_{H 2 O}$, for interfacial and bulk water regions (related to water structure rigidity or entropy), are 6 and 80 respectively. ${ }^{37}$ In this way, if $\varepsilon_{H 2 O}$ increases as a function of the distance from the electrode surface, then the ferrocenyl groups located on the dendrimers having the largest size (or Generation) will not only show the largest values for $K$, but also the smallest repulsive interactions $a>0$ between the adsorbates (as it can be observed in Table 2).

The relatively low values of $K$ presented in Table 2 can also be related to the small potential difference, $\Delta E^{0^{\prime}}$, between the formal redox potentials of the free $E_{f}^{0^{\prime}}$ and the complexed $E_{c}^{0 \prime}$ forms of ferrocene that was previously observed in Figure 3. As can be seen from the equilibrium reactions shown in Scheme 1, equation 13 can be used to relate $\Delta E^{\prime \prime}$ as a function of $K_{r e d}$ and $K_{o x}$, which represent the stability

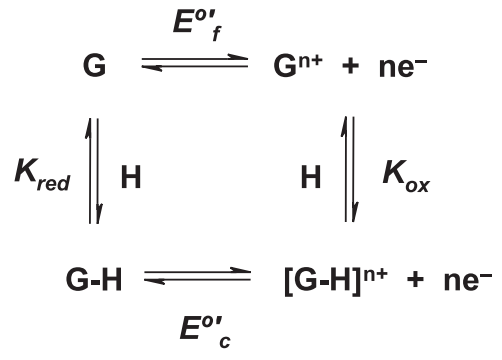

Scheme 1. Coupled electrochemical and chemical equilibria for an electroactive guest, $\mathrm{G},(\mathrm{Fc})$, with a non-electroactive host, $\mathrm{H},(\beta \mathrm{CD})$.

constants of the supramolecular complexes of the reduced and the oxidized forms of ferrocene, respectively. ${ }^{38}$

$\Delta E^{\mathrm{o}}=E_{c}^{0^{\prime}}-E_{f}^{0^{\prime}}=\frac{R T}{F} \ln \frac{K_{\text {red }}}{K_{o x}}$

If $K_{\text {red }}$ (the stability constant $K$ in equation 9) and $K_{o x}$ (which has been reported to be small since the $\beta \mathrm{CD}$ inclusion process for the oxidized ferrocene form is not a thermodynamically favored process) ${ }^{38}$ are small, then the $K_{\text {red }} / K_{o x}$ ratio tends to be one resulting in a $\Delta E^{0^{\prime}} c a$. 0 , i.e., close values of $E_{f}^{0^{\prime}}$ and $E_{c}^{0^{\prime}}$.

\section{Conclusions}

We have described the preparation of ferrocenyl tethered to PAMAM-dendrimer films on polycrystalline gold electrodes as a viable way for studying electrochemically the formation of the $1: 1 \mathrm{Fc} \bullet \beta \mathrm{CD}$ complex at an electrodeelectrolyte interface. In particular, this approach allows one to examine the effects of dendritic Generation on the binding and the lateral interactions between the adsorbates. The results obtained from the adsorption data revealed that the adsorbate-adsorbate interactions represent another variable that should be considered in describing the formation of the Fc $\bullet$ CD complexes in the electrode-electrolyte interfaces. This experimental approach may be useful for examining other guest-host molecular processes.

\section{Acknowlegments}

The authors are grateful to Consejo Nacional de Ciencia y Tecnología (CONACyT, grant 45157) for the financial support of this work. EB is also grateful to CONACyT for a doctoral scholarship. TWC is a CONACyT Cooperante in CIDETEQ under the sponsorship of the U.S. Peace Corps.

\section{References}

1. Kaifer, A. E.; Gómez-Kaifer, M.; Supramolecular Electrochemistry, Wiley-VCH: Weinheim, 1999. 
2. Saenger, W.; Angew. Chem. Int. Ed. Engl. 1980, 19, 344

3. Bersier, P. M.; Bersier, J.; Klingert, B.; Electroanalysis 1991, $3,443$.

4. Reetz, M. T.; J. Heterocyclic Chem. 1998, 35, 1065.

5. Frêchet, J. M.; Science 1994, 263, 1710.

6. Crooks, R. M.; Lemon III, B. I.; Sun, L.; Yeung, L. K.; Zhao, M.; Dendrimers: Design, Dimension and Function; SpringerVerlag; U.S.A; 2001.

7. Yoon, H. C.; Hong, M.-Y.; Kim, H.-S.; Anal. Chem. 2000, 72, 4420.

8. Yoon, H. C.; Hong, M.-Y.; Kim, H.-S.; Anal. Biochem. 2000, $282,121$.

9. Kim, E.; Kim, K.; Yang, H.; Kim, Y. T.; Kwak, J.; Anal. Chem. 2003, 75, 5665 .

10. Sato, S.; Nojima, T.; Kaki, M.; Takenaka, S.; Molecules 2005, $10,693$.

11. Yoon, H. C.; Lee, D.; Kim, H.-S.; Anal. Chim. Acta 2002, 456, 209.

12. Kwon, S. J.; Kim, E.; Yang, H.; Kwak, J.; Analyst 2006, 131, 402.

13. Astruc, D.; Daniel, M.-C.; Ruiz, J.; Chem. Commun. 2004, 2637.

14. Cardona, C. M.; McCarley, T. D.; Kaifer, A. E.; J. Org. Chem. 2000, 65, 1857.

15. Sabapathy, R. C.; Bhattacharyya, S.; Clealand, Jr., W. E.; Hussey, C. L.; Langmuir 1998, 14, 3797.

16. Godínez, L. A.; Castro, R.; Kaifer, A.E.; Langmuir 1996, 12, 5087.

17. Trasatti, S.; Petrii, O. A.; Pure Appl. Chem. 1991, 5, 711.

18. Manríquez, J.; Juaristi, E.; Muñoz-Muñiz, O.; Godínez, L. A.; Langmuir 2003, 19, 7315.

19. Summer, J. J.; Creager, S. E.; J. Phys. Chem. B 2001, 105, 8739.

20. Lee, L. Y. S. ; Lennox, B.; Langmuir 2007, 23, 292.

21. Ulman, A.; Chem. Rev. 1996, 96, 1533.

22. Arias, F.; Godínez, L. A.; Wilson, S. P.; Kaifer, A.; Echegoyen, L.; J. Am. Chem. Soc. 1996, 18, 6086.

23. Collinson, M.; Bowden, E. F.; Tarlov, M. J.; Langmuir 1992, $5,1247$.
24. Nijhuis, C. A.; Sinha, J. K.; Wittstock, G.; Huskens, J.; Ravoo, B. J.; Reinhoudt, D.N.; Langmuir 2006, 22, 9770.

25. Sabapathy, R. C.; Bhattacharryya, S.; Cleland Jr., W. E.; Hussey, C. L.; Langmuir 1998, 14, 3797.

26. Frumkin, A. N.; Damaskin, B. B. In Modern Aspects of Electrochemistry No. 3; Bockris, J. O’M., Conway, B. E., eds.; Butterworths: London, 1964.

27. Takada, K.; Díaz, D. J.; Abruña, H. D.; Cuadrado, I.; Casado, C.; Alonso, B.; Morán, M.; Losada, J.; J. Am. Chem. Soc. 1997, 119,10763

28. Takada, K.; Díaz, D. J.; Abruña, H. D.; Cuadrado, I.; González, B.; Casado, C. M.; Alonso, B.; Morán, M.; Losada, J.; Chem. Eur. J. 2001, 7, 1109.

29. Tang, L.; Zhu, Y.; Xu, L.; Yang, X.; Li, C.; Electroanalysis 2007, 19, 1677.

30. Crespilho, F. N.; Ghica, M. E.; Zucolotto, V.; Nart, F. C.; Oliveira Jr., O. N.; Brett, M. A. C.; Electroanalysis 2007, 19, 805.

31. Zhang, Y.; Zhao, C.; Yang, J.; Kapiamba, M.; Haze, O.; Rothberg, L. J.; Ng, M.-K.; J. Org. Chem. 2006, 71, 9475.

32. Kim, D. H.; Lee, O.-J.; Barriau, E.; Li, X.; Caminade, A.-M.; Majoral, J.-P.; Frey, H.; Knoll, W.; J. Nanosci. Nanotechnol. 2006, 6, 3871.

33. He, P.; Li, M.; Hu, N.; Biopolymers 2005, 79, 310.

34. Rekharsky, M. V.; Inoue, Y.; Chem. Rev. 1998, 98, 1875.

35. Inoue, Y.; Hakushi, T.; Tong, L.-H.; Shen, B.-J.; Jin, D.-S.; J. Am. Chem. Soc. 1993, 115, 475.

36. Jong, M. R.; Huskens, J.; Reinhoudt, D. N.; Chem. Eur. J. 2001, 7, 4164.

37. Bockris, J. O’M.; Reddy, A. K. N.; Gamboa-Aldeco, M.; Modern Electrochemistry 2A: Fundamentals of Electrodics, $2^{\text {nd }}$ ed.; Kluwer Academic: New York, 2000.

38. Mendoza, S.; Castaño, E.; Meas, Y.; Godínez, L.A.; Kaifer, A.E.; Electroanalysis 2004, 16, 1469.

Received: October 31, 2007 Web Release Date: May 30, 2008 